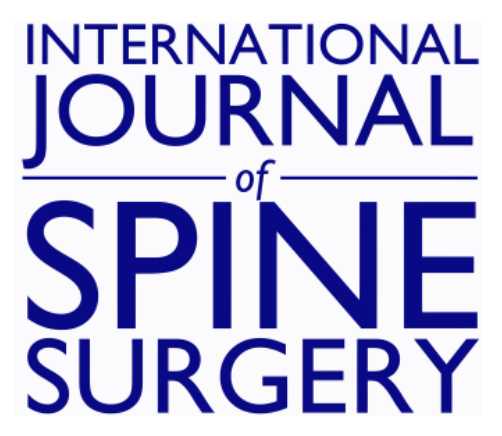

\title{
Multilevel Cervical Disc Arthroplasty: Long-Term Outcomes at 3 and 4 Levels
}

Matthew F. Gornet, Francine W. Schranck, Katrine M. Sorensen and Anne G. Copay

Int J Spine Surg 2020, 14 (s2) S41-S49

doi: https://doi.org/10.14444/7090

http://ijssurgery.com/content/14/s2/S41

This information is current as of April 26, 2023.

Email Alerts Receive free email-alerts when new articles cite this article. Sign up at:

http://ijssurgery.com/alerts

The International Journal of Spine Surgery

2397 Waterbury Circle, Suite 1,

Aurora, IL 60504, Phone: +1-630-375-1432 


\title{
Multilevel Cervical Disc Arthroplasty: Long-Term Outcomes at 3 and 4 Levels
}

\author{
MATTHEW F. GORNET, MD, ${ }^{1}$ FRANCINE W. SCHRANCK, BSN, ${ }^{2}$ KATRINE M. SORENSEN, MS, ${ }^{2}$ \\ ANNE G. COPAY, PHD \\ ${ }^{I}$ The Orthopedic Center of St Louis, St Louis, Missouri, ${ }^{2}$ SPIRITT Research, St Louis, Missouri
}

\begin{abstract}
Background: Multilevel cervical degenerative disc disease in 2 or more segments poses treatment challenges. Anterior cervical discectomy and fusion is a viable treatment option, but one with high rates of adjacent segment disease and pseudoarthrosis. Cervical disc arthroplasty (CDA) is approved by the US Food and Drug Administration for the treatment of 1- and 2-level cervical pathology, with established long-term safety and effectiveness. Limited evidence exists for CDA at more than 2 levels. This study investigates the long-term outcomes of 3- and 4-level CDA out to 7 years.

Methods: In a retrospective review of prospectively collected data, patient demographics and surgical characteristics were collected. Patient-reported outcomes (PROs) were collected preoperatively and at 6 weeks, 3 months, 6 months, and 12 months postoperatively, and annually thereafter, including: Neck Disability Index (NDI), numeric rating scales for neck pain and arm pain, the Veterans Rand 12-item Health Survey physical component summary (PCS) score and mental component summary (MCS) score, and patient satisfaction scores. Secondary surgery data were also collected. Predictive methods using mixed-effects regression models were used to analyze the data.

Results: Data for 139 CDAs were available for evaluation ( $n=116$ three-level and $n=23$ four-level). Statistical improvement was shown for all PRO scores at all postoperative intervals $(P<.001)$. From preoperatively to 7 years postoperatively, mean NDI decreased from 57.9 to 31.3 (45.9\% improvement), mean neck pain decreased from 15.6 to 7.9 (49.4\% improvement), mean arm pain decreased from 12.2 to 5.6 (54.1\% improvement), mean PCS increased from 29.2 to 41.4 (41.8\% improvement), and mean MCS increased from 37.1 to 44.5 (19.9\% improvement). Five (3.6\%) 3level patients underwent secondary surgery. Patient satisfaction exceeded $88 \% 7$ years after surgery.

Conclusion: Statistical improvement in PROs, with a low rate of secondary surgeries out to 7 years, demonstrates that 3- and 4-level CDA may be performed safely and effectively in appropriately selected patients.

Level of Evidence: 4.
\end{abstract}

Special Issue-Cervical Spine

Keywords: multilevel cervical disc replacement, cervical disc arthroplasty, 3- or 4-level CDA, ACDF, cervical fusion

\section{INTRODUCTION}

Cervical disc arthroplasty (CDA) has emerged as a proven alternative to anterior cervical discectomy and fusion (ACDF) to treat cervical degenerative disc disease (DDD) in appropriately selected patients. ${ }^{1-4}$ By preserving segmental motion, CDA has the potential to reduce the incidence of adjacent segment disease while mitigating nerve root compression by restoring both intervertebral disc and foraminal heights. ${ }^{5-9}$ Long-term clinical studies established the safety and effectiveness of singlelevel CDA, with superior clinical outcomes compared with ACDF. ${ }^{10-15}$ The safety and effectiveness of CDA at 2 contiguous levels have also been evidenced with long-term clinical outcomes reported up to 84 months. ${ }^{14-17}$ As a result of this large and growing body of evidence, more surgeons are choosing CDA for their patients.

ACDF has long been described as a gold standard treatment for cervical DDD. ${ }^{18-20}$ Particularly for patients with pathology at 2 or more cervical levels, ACDF still poses many treatment challenges, including a high incidence of adjacent segment disease resulting from increased stresses. Hypermobility and other biomechanical alterations have been associated with multilevel ACDF. ${ }^{21-23}$ In addition, high rates of pseudoarthrosis, associated with neck pain and other recurrent symptoms, have been reported for ACDF involving multiple levels. ${ }^{24,25}$ Unsuccessful fusion in multilevel constructs has been attributed to, among other factors, the greater surface area required for fusion, multiple 


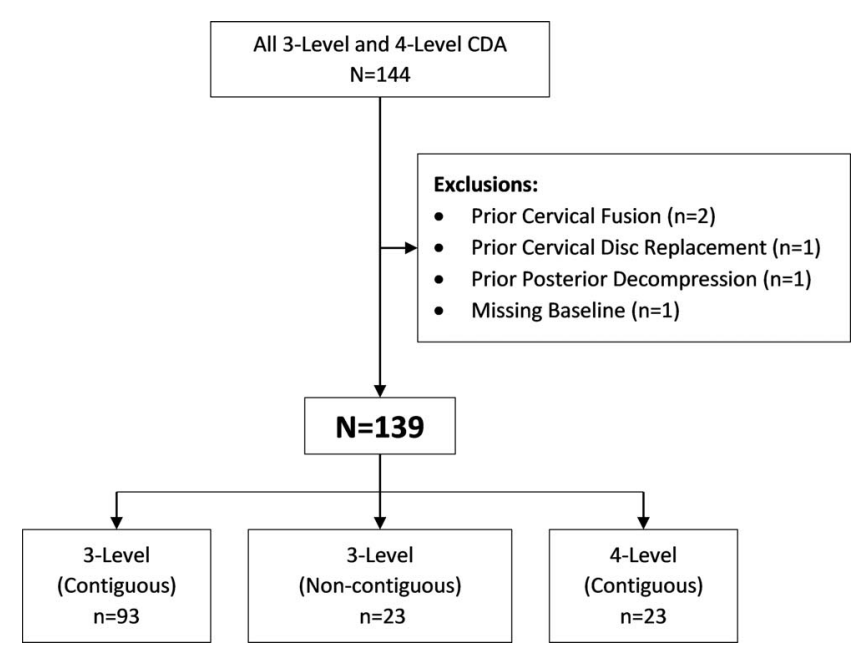

Figure 1. Patient flow chart.

hypermobile segments, and higher biomechanical loads across the fusion construct. ${ }^{24}$

In light of the extensive evidence now supporting the long-term safety of CDA at 1 or 2 levels, and the well-documented challenges after ACDF, surgeons are beginning to recognize that CDA has the potential to extend beyond 2 levels to treat multilevel cervical pathology. Some have reported positive CDA outcomes at 3 or 4 levels, but these studies have comprised very small cohorts and short follow-ups. ${ }^{21,26-28}$ Hence, the objective of the present study was to evaluate the long-term safety and effectiveness of 3-level and 4-level CDA in patients treated for cervical disc disease at more than 2 levels.

\section{PATIENTS AND METHODS}

This study was designed to assess the patientreported outcomes (PROs) of patients who underwent 3- or 4-level CDA. Data were collected prospectively following approval by an external Institutional Review Board. The study was conducted at 1 center by a single fellowship-trained surgeon. All patients were operated on at an ambulatory surgery center with 23-hour stay.

\section{Patients}

Of the total patients operated on between April 2008 and January 2018, 144 consecutive patients who underwent 3- or 4-level CDA were considered for this study (Figure 1). The artificial cervical disc designs used in this study included commercially available semiconstrained and unconstrained cervical discs based on patient suitability.
The inclusion criteria included a diagnosis of discogenic pain with or without radiculopathy and/ or myelopathy in patients who had been unresponsive to at least 6 weeks of conservative nonsurgical care. Patients undergoing 3- or 4- level CDA at either contiguous or noncontiguous levels were included. Any patients with prior cervical spine surgery or missing baseline data were excluded. A total of 5 patients were therefore excluded from the analysis.

\section{Materials}

Patient demographic, diagnostic, and surgical characteristics were collected for all enrolled patients. The following patient-reported outcomes were collected preoperatively and postoperatively at 6 weeks, 3 months, 6 months, and 12 months, and annually thereafter: Neck Disability Index (NDI), numeric rating scales for neck and arm pain (pain intensity + frequency, 0-20 points), and the Veterans Rand 12-item health survey (VR-12). The VR12 physical component summary (PCS) score and mental component summary (MCS) score were calculated. Patient satisfaction (5-point scale ranging from "definitely no" to "definitely yes") and patient global perceived effect (7-point scale from "vastly worsened" to "completely recovered") at each time point were also collected. All secondary surgeries were recorded for the safety assessment.

\section{Statistical Methods}

Mixed-effect regression models were used to assess the effect of time point on each PRO score after adjusting for age at surgery. These models effectively analyze the longitudinal data with repeated measures, allowing for irregularly timed intervals (eg, weekly, monthly, and yearly). The models yield a predicted PRO score for each patient at every time point, given there are no missing independent variables. Significance was set at $P=$ .05. Proprietary SpineSys Web-based data collection and database software (SPIRITT Research, St Louis, MO) was used for this study; statistical analysis was performed using SAS 9.4 (SAS Institute Inc, Cary, NC).

\section{RESULTS}

In this study, 139 patients were included and had data available for the evaluations. Patient accountability is reported in Figure 1. Of the patients 
Table 1. Operative levels description.

\begin{tabular}{lc}
\hline Levels & Patients, No. (\%) \\
\hline 3-Level & $116(83.45)$ \\
Contiguous & $93(66.91)$ \\
C3-C6 & $25(17.99)$ \\
C4-C7 & $67(48.20)$ \\
C5-T1 & $1(0.72)$ \\
Noncontiguous & $23(16.55)$ \\
C3-C4, C5-C7 & $19(13.67)$ \\
C3-C5, C6-C7 & $4(2.88)$ \\
4-Level & $23(16.55)$ \\
Contiguous C3-C7 & $23(16.55)$ \\
Total & $139(100)$ \\
\hline
\end{tabular}

operated on at 3 levels, most surgeries were at contiguous levels from $\mathrm{C} 4$ to $\mathrm{C} 7$; the second most common was $\mathrm{C} 3$ to $\mathrm{C} 6$. A low number of 3-level surgeries were at noncontiguous segments $\mathrm{C} 3$ to $\mathrm{C} 4$ with $\mathrm{C} 5$ to $\mathrm{C} 7$, or $\mathrm{C} 3$ to $\mathrm{C} 5$ with $\mathrm{C} 6$ to $\mathrm{C} 7$ (Table 1).

This patient population was $56.8 \%$ male, with an average age of $48.84 \pm 9.49$ years and average body mass index of $29.55 \pm 5.37 \mathrm{~kg} / \mathrm{m}^{2}$ (Table 2). The average operative time was $158.68 \pm 41.96$ minutes, and mean estimated blood loss was $48.92 \pm 9.46$ $\mathrm{mL}$. Figures 2 and 3 display the preoperative and postoperative imaging studies of 2 illustrative 4-level patients.

Predictive methods using mixed-effects regression models demonstrated statistically significant improvement in all evaluated PRO scores from baseline to follow-up, at all postoperative intervals
( $P<.001$ at all time points). The effect of age at surgery was statistically significant in the model for each outcome measure, except for neck pain $(P=$ .195). From preoperatively to 7 years postoperatively, the output for each outcome measure analyzed was as follows: the mean NDI score decreased from 57.9 to 31.3 (45.9\% improvement); the mean neck pain score decreased from 15.6 to 7.9 (49.4\% improvement); the mean arm pain score decreased from 12.2 to 5.6 (54.1\% improvement); mean PCS increased from 29.2 to 41.4 (41.8\% improvement); and mean MCS increased from 37.1 to 44.5 (19.9\% improvement). Statistical improvement in PROs was observed at 6 weeks and was maintained through 7 years postoperatively. Figure 4 shows the mixed-effects regression model results at each individual time point. Patient satisfaction was also consistently strong at each postoperative time point; at 7 years, $88.2 \%$ of patients were definitely or mostly satisfied with their surgery; $82.4 \%$ of patients reported to be completely recovered or much improved.

Heterotopic ossification (HO) levels of grade 3 or grade 4 were observed in 21 of 122 patients $(17.2 \%)$ for whom x-rays were available 1 or more years after surgery. Of the 387 total levels treated with CDA in those 122 patients, grade 3 or grade $4 \mathrm{HO}$ was observed at 34 , or $8.8 \%$, of all treated levels.

Table 2. Demographic characteristics.

\begin{tabular}{|c|c|c|c|}
\hline & 3- and 4-Level $(\mathrm{N}=139)$ & 3-Level $(n=116)$ & 4-Level $(n=23)$ \\
\hline Age at surgery, $\mathrm{y}$ & $48.84 \pm 9.49$ & $47.99 \pm 9.57$ & $53.13 \pm 7.94$ \\
\hline $\mathrm{BMI}, \mathrm{kg} / \mathrm{m}^{2}$ & $29.55 \pm 5.37$ & $29.69 \pm 5.54$ & $28.82 \pm 4.46$ \\
\hline Male, No. ( $\%)$ & $79(56.83)$ & $62(53.45)$ & $17(73.91)$ \\
\hline \multicolumn{4}{|l|}{ Race, No. $(\%)$} \\
\hline White & $113(81.29)$ & $93(80.17)$ & $20(86.96)$ \\
\hline Black or African American & $19(13.67)$ & $16(13.79)$ & $3(13.04)$ \\
\hline Not specified & $3(2.16)$ & $3(2.59)$ & $0(0.00)$ \\
\hline Asian & $1(0.72)$ & $1(0.86)$ & $0(0.00)$ \\
\hline Asian and white & $1(0.72)$ & $1(0.86)$ & $0(0.00)$ \\
\hline Hispanic or Latino/a & $1(0.72)$ & $1(0.86)$ & $0(0.00)$ \\
\hline Other & $1(0.72)$ & $1(0.86)$ & $0(0.00)$ \\
\hline \multicolumn{4}{|l|}{ Marital status, No. (\%) } \\
\hline Married/engaged & 87 (62.59) & $70(60.34)$ & $17(73.91)$ \\
\hline Divorced/separated & $23(16.55)$ & $18(15.52)$ & $5(21.74)$ \\
\hline Single & $23(16.55)$ & $22(18.97)$ & $1(4.35)$ \\
\hline Not specified & $2(1.44)$ & $2(1.72)$ & $0(0.00)$ \\
\hline Living with partner & $2(1.44)$ & $2(1.72)$ & $0(0.00)$ \\
\hline Widowed & $1(0.72)$ & $1(0.86)$ & $0(0.00)$ \\
\hline Unknown & $1(0.72)$ & $1(0.86)$ & $0(0.00)$ \\
\hline \multicolumn{4}{|l|}{ Education, No. (\%) } \\
\hline Less than high school diploma or GED & $11(7.91)$ & $10(8.62)$ & $1(4.35)$ \\
\hline High school diploma or GED & $74(53.24)$ & $64(55.17)$ & $10(43.48)$ \\
\hline Technical school or associate's degree & $32(23.02)$ & $25(21.55)$ & $7(30.43)$ \\
\hline 4-year college degree & $16(11.51)$ & $14(12.07)$ & $2(8.70)$ \\
\hline Graduate or professional degree & $6(4.32)$ & $3(2.59)$ & $3(13.04)$ \\
\hline
\end{tabular}

Abbreviation: BMI, body mass index 


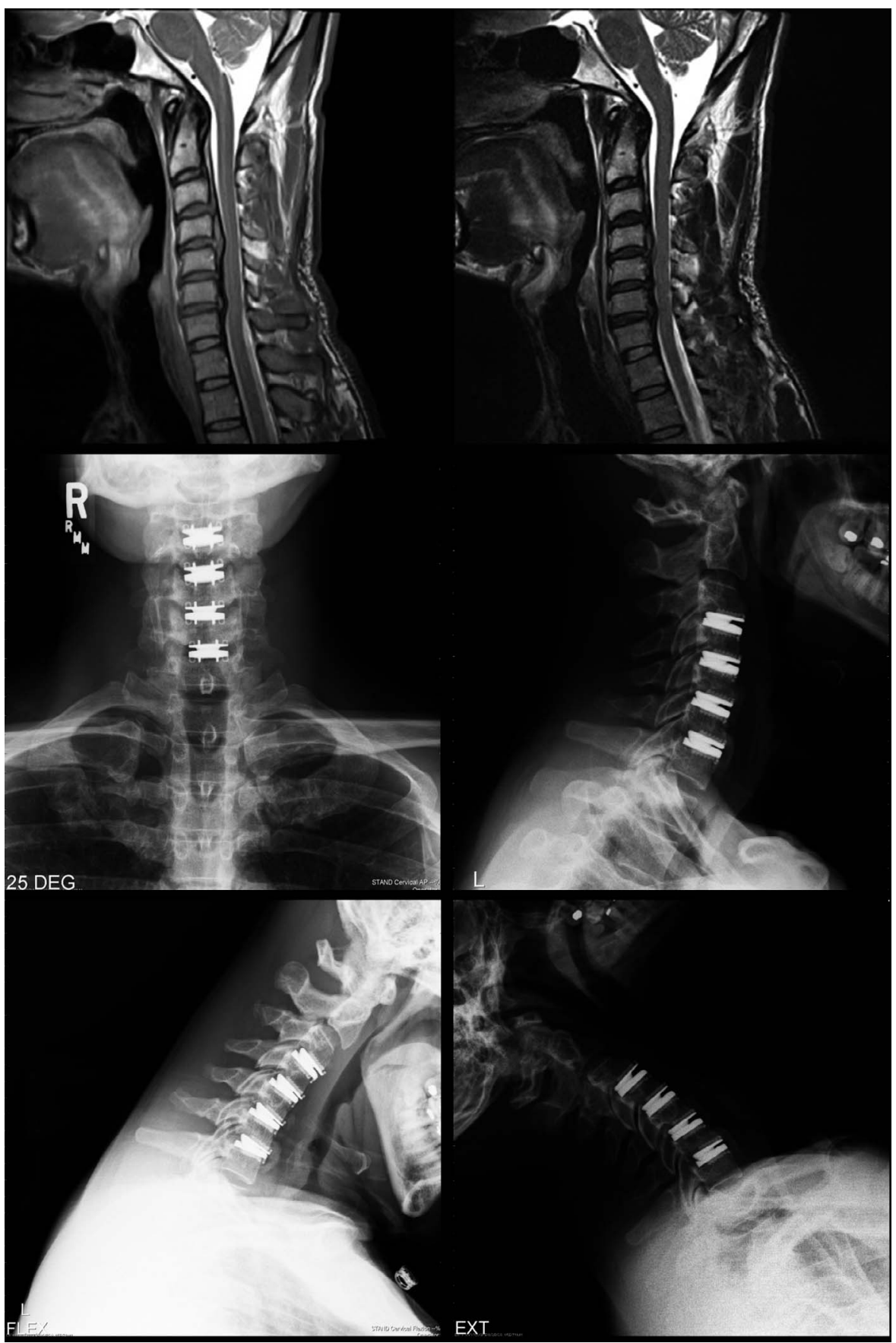

Figure 2. Illustrative patient: preoperative imaging studies reveal disease at 4 levels. No other treatment option available except decompression and fusion.

Five 3-level patients $(3.60 \%)$ underwent a secondary surgery at an average of $13.80 \pm 9.42$ months after the index surgery (Table 3 ). Three of these patients had increased pain and underwent decompression surgery at 6,14 , and 25 months postoperatively. The 2 other patients experienced device subsidence. One patient (C4-C7) had subsidence at $\mathrm{C} 5$ to $\mathrm{C} 6$ and underwent implant removal, and subsequent anterior/posterior fusion, at $\mathrm{C} 4$ to C6, 21 months after the index surgery. The other patient (C3-C4, C5-C7) had subsidence at $\mathrm{C} 4$ to $\mathrm{C} 5$ and underwent an implant replacement after 3 months. No secondary surgeries were reported for 4-level patients.

\section{DISCUSSION}

ACDF has been the standard of care to treat cervical disc disease since the 1950s. ${ }^{29-33}$ However, ACDF has been shown to alter natural spinal 


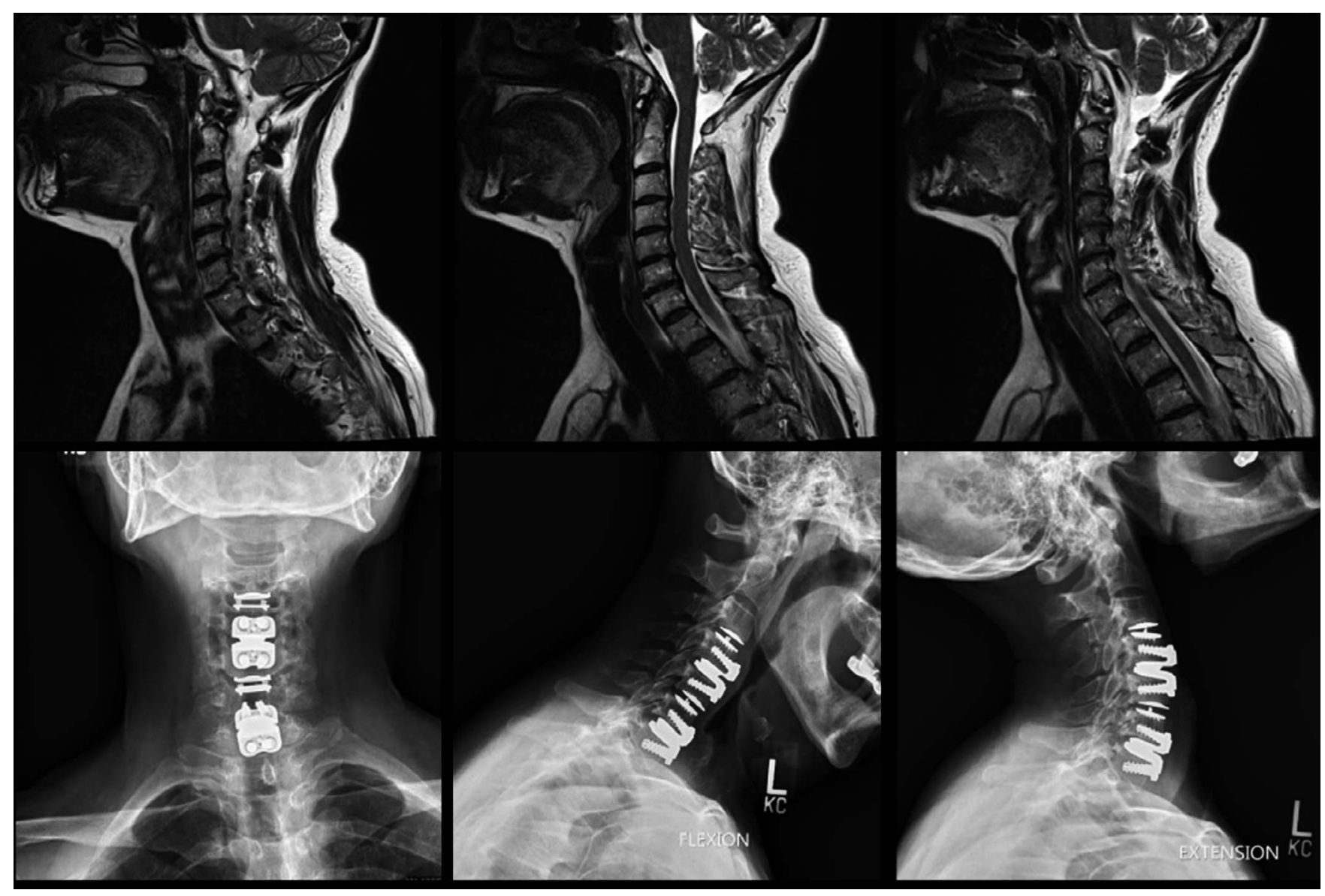

Figure 3. Illustrative patient: preoperative imaging studies reveal disease at 4 levels. No other treatment option available except decompression and fusion.

biomechanics, leading to adjacent segment degeneration and the recurrence of radiculopathy in up to $25 \%$ of patients. ${ }^{34-37}$ The ACDF procedure intentionally restricts motion at the fused levels, thereby introducing abnormal loads, increased intradiscal pressure, stresses, and hypermotion at the levels adjacent to fusion. ${ }^{22}$ For patients with multilevel disc degeneration, multilevel ACDF has been considered the most viable treatment modality, despite its limitations. In a recently published study, reductions of $26.1 \%$ in NDI, 33.4\% in neck pain, and $50.4 \%$ in arm pain were reported for multilevel ACDF at 24 months. ${ }^{38}$ However, multilevel ACDF may cause even greater stresses to adjacent discs, and, compared with single-level ACDF, multilevel ACDF yields higher rates of pseudarthrosis, complications, revisions, and reoperations. The 24month reoperation rate has been reported elsewhere to be $35 \%$ for patients who underwent 3 - and 4-level cervical fusion. ${ }^{38}$ In an effort to preserve segmental motion, both multilevel CDA and a hybrid surgical treatment combining CDA and ACDF have been considered. However, the preference of either of these motion-sparing treatments is dependent on the severity of disc degeneration and optimized patient selection.

A hybrid surgical treatment has been shown in some reports to be a promising alternative to multilevel ACDF, with comparable PROs and the preservation of a normal range of motion at 24 months and beyond. ${ }^{22,39}$ However, long-term outcomes have not been reported. For appropriately selected DDD patients, multilevel CDA could be a desirable alternative to multilevel ACDF that preserves segmental motion. The most favorable outcomes of CDA depend on optimized patient selection, which might include preoperative disc height of at least $3 \mathrm{~mm}$, little or no facet joint degeneration or instability, and no confirmed osteoporosis (T-score greater than -1.5$).{ }^{40}$

The safety and efficacy of CDA as a treatment for both single- and 2-level cervical disc disease is now well established in the literature. There have been several clinical investigations comparing the safety and efficacy of single-level and multilevel CDA. With no statistical difference in the PROs, a 

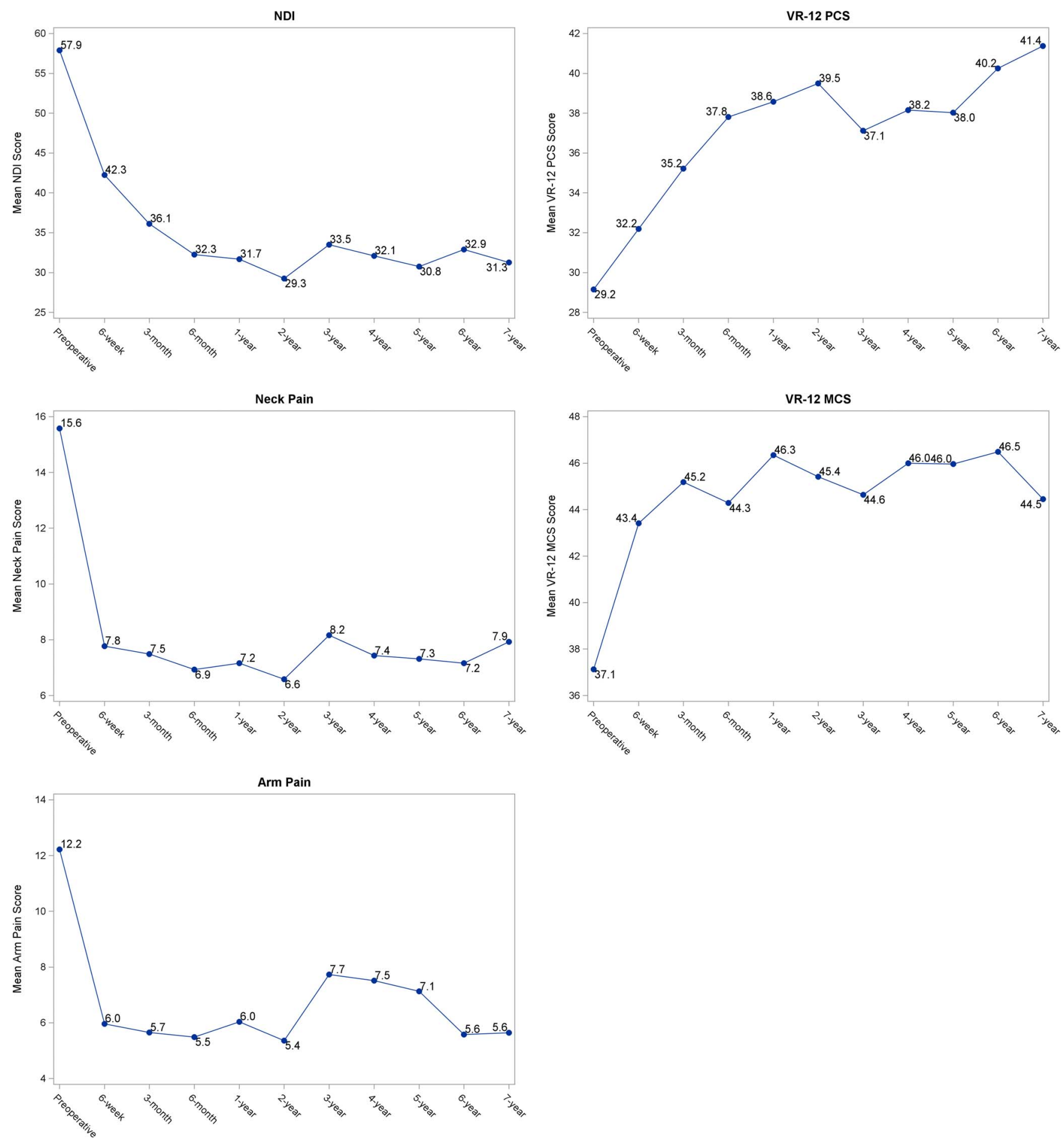

Figure 4. Predicted mean patient reported outcomes scores.

comparison of clinical outcomes at a single level and at multiple levels (2 levels or more) up to 48 months showed initial safety and effectiveness for the multilevel CDA. ${ }^{21,41}$ In a retrospective review, Friesem et $\mathrm{al}^{26}$ reported significant improvement in NDI, VAS neck and VAS arm scores for 3- and 4level patients at 62 months. This study also compared outcomes for 3- and 4-level patients and 1- and 2-level patients and found similar -improvement in both groups. In contrast to the studies referenced above, Pimenta et $\mathrm{al}^{27}$ found significantly improved clinical outcomes for multilevel CDA compared with single-level CDA. However, most of these reported outcomes have been limited by small 
Table 3. Secondary surgeries.

\begin{tabular}{|c|c|c|c|c|}
\hline Index Surgery Date & $\begin{array}{c}\text { Index } \\
\text { Operative Levels }\end{array}$ & Secondary Surgery Date & $\begin{array}{l}\text { Secondary Surgery } \\
\text { Operative Levels }\end{array}$ & Secondary Surgery Description \\
\hline December 8, 2010 & $\mathrm{C} 4-\mathrm{C} 7$ & January 29, 2013 & C6-7 & Laminotomy and foraminotomy \\
\hline October 10,2012 & $\mathrm{C} 4-\mathrm{C} 7$ & April 30,2013 & $\mathrm{C} 4-7$ & Laminotomy and foraminotomy \\
\hline November 30,2011 & $\mathrm{C} 4-\mathrm{C} 7$ & September 4, 2013 & $\mathrm{C} 4-\mathrm{C} 6$ & $\begin{array}{l}\text { Disc replacement removal, anterior fusion, } \\
\text { posterior fusion }\end{array}$ \\
\hline January 15, 2014 & $\mathrm{C} 3-\mathrm{C} 4, \mathrm{C} 5-\mathrm{C} 7$ & May 13, 2014 & $\mathrm{C} 4-5$ & Hardware removal and disc replacement \\
\hline February 10,2015 & $\mathrm{C} 3-\mathrm{C} 6$ & May 3, 2016 & C3-6 & Keyhole foraminotomy, left \\
\hline
\end{tabular}

patient cohorts and short follow-ups. The results of the current study provide long-term clinical evidence that is consistent with previously reported, shorter duration improvement in clinical outcomes for CDA at more than 2 levels, confirming the longterm safety and effectiveness of CDA for these patients.

In the current study, grade 3 or grade $4 \mathrm{HO}$ was reported in $17.2 \%$ of patients. A prior comparison of single-level CDA with 2-level CDA, with or without a fused level, concluded that $\mathrm{HO}$ occurrence increased with multilevel CDA but that $\mathrm{HO}$ did not affect the outcomes. In the current study, the statistical improvement in patient-reported outcomes and the rarity of secondary surgeries similarly indicate that $\mathrm{HO}$, where present, remained mainly asymptomatic.

CDA, as a frontline surgical treatment for cervical disc degeneration, has gained credibility after taking into account the favorable outcomes consistent with long-term functional recovery, the rate of adverse events, the onset of adjacent segment disease, and the rate of subsequent surgeries. ${ }^{42}$ In the United States, CDA has experienced a high rate of annual growth in its use both as a primary therapy $(20.54 \%)$ and revision therapies (5.84\%), attributed to better PROs compared with ACDF. ${ }^{43}$ $\mathrm{CDA}$ as a good alternative to ACDF is further supported by the results of this current study. To our knowledge, this is the largest reported cohort to date of 3- and 4-level CDA patients reporting longterm clinical outcomes. In appropriately selected patients, the significant PRO improvement, high patient satisfaction, and low secondary surgeries, supplemented by the enhanced durability of CDA compared with ACDF, ${ }^{44}$ support the viability of CDA at more than 2 levels.

The present study is not without limitations. First, this is a single-arm exploratory study with no opportunity for comparison to other treatment modalities. Second, this is a community-based, real conditions of use study at a single center. Although there is considerable value in the tracking of longterm outcomes in a non-US Food and Drug Administration cohort, patients at this center may not be generalizable to the population at large.

\section{CONCLUSION}

Only a few multilevel studies have reported on 3and 4-level CDA, and long-term clinical data have not been reported in the literature. To our knowledge, this is the first study reporting on the long-term clinical outcomes of 3- and 4-level CDA, and the largest 3- and 4-level patient cohort to date. For appropriately selected patients with cervical DDD at more than 2 levels, CDA is safe and effective, and it may provide statistical improvement in patient-reported outcomes, high patient satisfaction, and low rates of secondary surgery.

\section{ACKNOWLEDGMENTS}

The study's source of funding is investigatorsponsored research. Institutional Review Boad: Western IRB (protocol No. 20080163; study No. SR-2013-02).

\section{REFERENCES}

1. Joaquim AF, Makhni MC, Riew KD. Evidence-based use of arthroplasty in cervical degenerative disc disease. Int Orthop. 2019;43(4):767-775.

2. Gao F, Mao T, Sun W, et al. An updated meta-analysis comparing artificial cervical disc arthroplasty (CDA) versus anterior cervical discectomy and fusion (ACDF) for the treatment of cervical degenerative disc disease (CDDD). Spine. 2015;40(23):1816-1823.

3. Xie L, Liu M, Ding F, et al. Cervical disc arthroplasty (CDA) versus anterior cervical discectomy and fusion (ACDF) in symptomatic cervical degenerative disc diseases (CDDDs): an updated meta-analysis of prospective randomized controlled trials (RCTs). SpringerPlus. 2016;5(1):1188. doi:10.1186/ s40064-016-2851-8

4. Zhang Y, Liang C, Tao Y, et al. Cervical total disc replacement is superior to anterior cervical decompression and fusion: a meta-analysis of prospective randomized controlled trials. PloS One. 2015;10(3):e0117826. 
5. Botelho RV, Moraes OJ, Fernandes GA, et al. A systematic review of randomized trials on the effect of cervical disc arthroplasty on reducing adjacent-level degeneration. Neurosurg Focus. 2010;28(6):E5.

6. Gao Y, Liu M, Li T, et al. A meta-analysis comparing the results of cervical disc arthroplasty with anterior cervical discectomy and fusion (ACDF) for the treatment of symptomatic cervical disc disease. J Bone Joint Surg Am. 2013;95(6):555561.

7. Kasliwal MK, Traynelis VC. Motion preservation in cervical spine: review. J Neurosurg Sci. 2012;56(1):13-25.

8. Rao MJ, Nie SP, Xiao BW, et al. Cervical disc arthroplasty versus anterior cervical discectomy and fusion for treatment of symptomatic cervical disc disease: a metaanalysis of randomized controlled trials. Arch Orthop Trauma Surg. 2015;135(1):19-28.

9. McAfee PC. The indications for lumbar and cervical disc replacement. Spine J. 2004;4(6 suppl):177S-181S.

10. Gornet MF, Burkus JK, Shaffrey ME, et al. Cervical disc arthroplasty with Prestige LP disc versus anterior cervical discectomy and fusion: seven-year outcomes. Int J Spine Surg. 2016;10:24. doi:10.14444/3024

11. Burkus JK, Traynelis VC, Haid RW, et al. Clinical and radiographic analysis of an artificial cervical disc: 7-year followup from the Prestige prospective randomized controlled clinical trial: clinical article. J Neurosurg Spine. 2014;21(4):516-528.

12. Loumeau TP, Darden BV, Kesman TJ, et al. A RCT comparing 7-year clinical outcomes of one level symptomatic cervical disc disease (SCDD) following ProDisc-C total disc arthroplasty (TDA) versus anterior cervical discectomy and fusion (ACDF). Eur Spine J. 2016;25(7):2263-2270.

13. Lavelle WF, Riew KD, Levi A, et al. 10-year outcomes of cervical disc replacement with the BRYAN ${ }^{\circledR}$ Cervical Disc: results from a prospective, randomized, controlled clinical trial. Spine. (Phila Pa 1976). 2019;44(9):601-608.

14. Radcliff K, Davis RJ, Hisey MS, et al. Long-term evaluation of cervical disc arthroplasty with the Mobi-C(C) Cervical Disc: a randomized, prospective, multicenter clinical trial with seven-year follow-up. Int $J$ Spine Surg. 2017;11(4):244-262.

15. Jackson RJ, Davis RJ, Hoffman GA, et al. Subsequent surgery rates after cervical total disc replacement using a MobiC Cervical Disc Prosthesis versus anterior cervical discectomy and fusion: a prospective randomized clinical trial with 5-year follow-up. J Neurosurg Spine. 2016;24(5):734-745.

16. Lanman TH, Burkus JK, Dryer RG, et al. Long-term clinical and radiographic outcomes of the Prestige LP artificial cervical disc replacement at 2 levels: results from a prospective randomized controlled clinical trial. J Neurosurg Spine. 2017;27(1):7-19.

17. Davis RJ, Nunley PD, Kim KD, et al. Two-level total disc replacement with Mobi-C cervical artificial disc versus anterior discectomy and fusion: a prospective, randomized, controlled multicenter clinical trial with 4-year follow-up results. J Neurosurg Spine. 2015;22(1):15-25.

18. Gutman G, Rosenzweig DH, Golan JD. Surgical treatment of cervical radiculopathy: meta-analysis of randomized controlled trials. Spine. 2018;43(6):E365-E372.

19. Zou S, Gao J, Xu B, et al. Anterior cervical discectomy and fusion (ACDF) versus cervical disc arthroplasty (CDA) for two contiguous levels cervical disc degenerative disease: a meta- analysis of randomized controlled trials. Eur Spine $J$. 2017;26(4):985-997.

20. Nabhan A, Ahlhelm F, Shariat K, et al. The ProDisc-C Prothesis. Spine. 2007;32(18):1935-1941.

21. Huppert J, Beaurain J, Steib JP, et al. Comparison between single- and multi-level patients: clinical and radiological outcomes 2 years after cervical disc replacement. Eur Spine J. 2011;20(9):1417-1426.

22. Zhang J, Meng F, Ding Y, et al. Hybrid surgery versus anterior cervical discectomy and fusion in multilevel cervical disc diseases: a meta-analysis. Medicine (Baltimore). 2016;95(21):e3621.

23. Wu TK, Wang BY, Meng Y, et al. Multilevel cervical disc replacement versus multilevel anterior discectomy and fusion: a meta-analysis. Medicine (Baltimore). 2017;96(16):e6503.

24. Kreitz TM, Hollern DA, Padegimas EM, et al. Clinical outcomes after four-level anterior cervical discectomy and fusion. Glob Spine J. 2018;8(8):776-783.

25. Li Y, Shen H, Khan KZ, et al. Comparison of multilevel cervical disc replacement and multilevel anterior discectomy and fusion: a systematic review of biomechanical and clinical evidence. World Neurosurg. 2018;116:94-104.

26. Friesem T, Khan S, Rajesh M, et al. Long term follow up of multi-level (three \& four levels) cervical disc arthroplastyresults from a single centre. Spine J. 2017;17(3):S28-S29.

27. Pimenta L, McAfee PC, Cappuccino A, et al. Superiority of multilevel cervical arthroplasty outcomes versus single-level outcomes: 229 consecutive PCM prostheses. Spine. 2007;32(12):1337-1344.

28. Sekhon LHS, Sears W, Duggal N. Cervical arthroplasty after previous surgery: results of treating 24 discs in 15 patients. J Neurosurg Spine. 2005;3(5):335-341.

29. Bohlman HH, Emery SE, Goodfellow DB, et al. Robinson anterior cervical discectomy and arthrodesis for cervical radiculopathy: long-term follow-up of one hundred and twenty-two patients. J Bone Joint Surg Am. 1993;75(9):12981307.

30. Brodke DS, Zdeblick TA. Modified Smith-Robinson procedure for anterior cervical discectomy and fusion. Spine. 1992;17(10 suppl):S427-S430.

31. Fraser JF, Härtl R. Anterior approaches to fusion of the cervical spine: a metaanalysis of fusion rates. J Neurosurg Spine. 2007;6(4):298-303.

32. Smith GW, Robinson RA. The treatment of certain cervical-spine disorders by anterior removal of the intervertebral disc and interbody fusion. J Bone Joint Surg Am. 1958;40A(3):607-624.

33. Brown JA, Havel P, Ebraheim N, et al. Cervical stabilization by plate and bone fusion. Spine. 1988;13(3):236 240.

34. Hilibrand AS, Robbins M. Adjacent segment degeneration and adjacent segment disease: the consequences of spinal fusion? Spine J. 2004;4(6 suppl):190S-194S. doi:10.1016/j. spinee.2004.07.007

35. Robertson JT, Papadopoulos SM, Traynelis VC. Assessment of adjacent-segment disease in patients treated with cervical fusion or arthroplasty: a prospective 2-year study. $J$ Neurosurg Spine. 2005;3(6):417-423.

36. Dmitriev AE, Cunningham BW, Hu N, et al. Adjacent level intradiscal pressure and segmental kinematics following a 
cervical total disc arthroplasty: an in vitro human cadaveric model. Spine. 2005;30(10):1165-1172.

37. Kulkarni V, Rajshekhar V, Raghuram L. Accelerated spondylotic changes adjacent to the fused segment following central cervical corpectomy: magnetic resonance imaging study evidence. J Neurosurg. 2004;100(1 suppl):2-6.

38. Laratta JL, Reddy HP, Bratcher KR, et al. Outcomes and revision rates following multilevel anterior cervical discectomy and fusion. J Spine Surg. 2018;4(3):496-500.

39. Zhu Y, Fang J, Xu G, et al. A hybrid technique for treating multilevel cervical myelopathy: cervical artificial disc replacement combined with fusion. Oncol Lett. 2019;17(1):360364.

40. Joaquim AF, Riew KD. Multilevel cervical arthroplasty: current evidence: a systematic review. Neurosurg Focus. 2017;42(2):E4.

41. Bae HW, Kim KD, Nunley PD, et al. Comparison of clinical outcomes of 1- and 2-level total disc replacement: fouryear results from a prospective, randomized, controlled, multicenter IDE clinical trial. Spine. 2015;40(11):759-766.

42. Badve SA, Nunley PD, Kurra S, et al. Review of longterm outcomes of disc arthroplasty for symptomatic single level cervical degenerative disc disease. Expert Rev Med Devices. 2018;15(3):205-217.

43. Niedzielak TR, Ameri BJ, Emerson B, et al. Trends in cervical disc arthroplasty and revisions in the Medicare database. J Spine Surg. 2018;4(3):522-528.

44. Chen C, Zhang X, Ma X. Durability of cervical disc arthroplasties and its influence factors. Medicine (Baltimore). 2017;96(6):e5947.

Disclosures and COI: Dr Gornet is a consultant for Aesculap; has stock in or is a shareholder of Bonovo, Nocimed, OuroBorus, Paradigm Spine, RTI, and the International Spine and Orthopedic Institute; and has received grant/research support and other financial support from and is a consultant for Medtronic. Ms Schranck has stock in or is a shareholder of Nocimed. Ms Sorensen and Dr Copay report no conflicts of interest.

Corresponding Author: Matthew F. Gornet, MD, The Orthopedic Center of St Louis, 14825 North Outer Forty Road, Suite 200, St Louis, MO 63017. Phone: (314) 324-5482; Email: mfgspine@ gmail.com.

Published 30 September 2020

This manuscript is generously published free of charge by ISASS, the International Society for the Advancement of Spine Surgery. Copyright (C) 2020 ISASS. To see more or order reprints or permissions, see http://ijssurgery.com. 